\title{
A AUTORIDADE LUTERANO-CALVINISTA COMO FUNDAMENTAÇÃO MORAL PARA A ESCOLA SEM PARTIDO A PARTIR DO EXPOSTO POR MARCUSE
}

\author{
THE LUTHER AND CALVIN'S AUTHORITY AS MORALITY FONDATION FOR \\ SCHOOL WITHOUT PARTY BASED ON MARCUSE
}

\author{
Manoel Dionízio Neto ${ }^{1}$
}

\section{Resumo}

Herbert Marcuse, em seu livro "Ideias sobre uma teoria crítica da sociedade", leva-nos a refletir sobre a concepção de autoridade em Lutero e Calvino como fundamento para se pensar a moral requerida pelo Movimento Escola Sem Partido. Para tanto, considere-se, por um lado, a concepção de liberdade desses reformistas, por outro, a concepção de educação e de escola desse Movimento. Assim, a fundamentação moral que se encontra no Movimento Escola Sem Partido funda-se na concepção de liberdade de Lutero e Calvino, quando nela está presente toda fundamentação moral que orienta o comportamento dos cristãos. Isto equivale a dizer que a orientação para a formação que se deve encontrar na escola proposta por esse Movimento segue as coordenadas do pensamento dos reformistas aqui em questão. Para se estabelecer a relação entre o que propõem este Movimento e o pensamento desses reformistas, busca-se o exposto por eles e os seus seguidores, assim como o que pensam diferentes educadores e críticos a respeito da significação para a formação humana, o que está posto em diferentes Projetos de uma escola, onde se tem que simplesmente obedecer sem questionamento o que for proposto (ou imposto) pela direção dessa escola ou gestores do ensino, considerando-se estes numa hierarquia que começa na referida direção escolar, estendendo-se à escala mais alta da administração governamental.

Palavras-chave: Marcuse; Lutero; Calvino; Escola Sem Partido; Autoridade.

\begin{abstract}
Herbert Marcuse, in his book Towards a Critical Theory of Society "Ideen zu einer kritischen Theorie der Gesellschaft", leads us to reflect on Luther and Calvin's conception of authority as foundation for thinking about the morality on School Without Party Movement (Movimento Escola Sem Partido). To do so, we should consider these Reformers' conception of freedom and the Movement's conception of education and of school. So, the School Without Party Movement's morality foundation is based on Luther and Calvin's conception of freedom, in which is presented all morality foundation that guides the Christians' behavior.
\end{abstract}

\footnotetext{
${ }^{1}$ Universidade Federal de Campina Grande -PB - dionizioneto@uol.com.br
} 


\section{OO DEVIR EDUCAÇÃO \\ ISSN: 2526-849X}

This equals to say that the orientation for formation that one will find on the school proposed by this Movement follows the coordinates of the alluded Reformers' thinking. In order to establish the relationship between the Movement propositions and the Reformers' thinking, we search what was stated by them and their followers, as well as what different educators and critics think about the meaning for human formation, presented in different school projects, where one has to simply obey without question what is proposed (or imposed) by the school principal or managers, considering them in a hierarchy that begins with the said school principal, extending to government administration.

Keywords: Marcuse; Luther; Calvin; School Without Party; Authority.

\section{Introdução}

Para se pensar a questão da autoridade em Lutero e Calvino como fundamento para se pensar a moral requerida pelo Movimento Escola Sem Partido tomando-se o exposto por Marcuse em seu livro "Ideias sobre uma teoria crítica da sociedade", é preciso considerar: a concepção de liberdade desses reformistas, os fundamentos morais a partir da sua concepção de liberdade e a concepção de educação e de escola desse Movimento.

Herbert Marcuse chama a atenção para o que significa liberdade e não-liberdade, bem como a autonomia e a heteronomia, a partir da questão da autoridade e do seu objeto, conforme os pensamentos de Lutero e Calvino. E nesses termos, depara-se com a sua condição paradoxal aquele que se relaciona com essa autoridade em sua condição de objeto: o mesmo cristão que "é senhor livre sobre todas as coisas e não está sujeito a ninguém" é, ao mesmo tempo, "servidor de todas as coisas e sujeito a todos" (LUTERO, 1979, p. 9). Como, então, compreender o sentido deste paradoxo? Compreende-se esse paradoxo, segundo Marcuse, tendo-se em vista a questão da autonomia posta pela teoria burguesa como autonomia da pessoa em geral que fora colocada no centro dessa teoria pela filosofia burguesa. Assim o paradoxo da liberdade e da não-liberdade, enquanto unificação da autonomia e heteronomia na mesma pessoa, se fez notar a partir do surgimento da Modernidade, quando se dá a ascensão da burguesia tanto econômica como politicamente. Conclui-se então que a burguesia, desde os seus primeiros voos em direção à conquista e manutenção do poder, necessitava do estabelecimento desse paradoxo naqueles que dariam sustentação ao sistema de produção capitalista na condição de trabalhadores assalariados.

Chega-se, pois, a esse entendimento, conforme o exposto por Marcuse, quando a interpretação dele é confrontada com o exposto pelos reformadores aqui referidos: Lutero e Calvino, sobre a liberdade. E é justamente o entendimento deles que nos coloca diante do 


\section{QO DEVIR EDUCAÇÃO \\ ISSN: 2526-849X}

paradoxo aqui referido. Daí se fazer necessária a relação do que pensa o Movimento Escola Sem Partido sobre a educação e a escola com o que dizem estes reformistas sobre a fundamentação moral que tem por base a sua concepção de liberdade.

\section{A concepção de liberdade de Lutero e Calvino}

Segundo Martin Lutero (1979, p. 9-10), "Para se poder entender ambas afirmações entre si diretamente contraditórias, sobre a liberdade e a servidão, deveremos ter em conta que todo cristão possui uma natureza espiritual e outra corporal". De acordo com este entendimento, primeiro, ser cristão não é mesma coisa de ser humano, independentemente de suas convicções religiosas; segundo, o cristão, ao se reconhecer e ao ser reconhecido a partir do seu corpo próprio, deve ser consciente de que, enquanto ser corporal que é, está disponível à escravidão, devendo se submeter a todo serviço que a ele for imposto. E ele tem apenas a obrigação de obedecer, uma vez que a sua liberdade, enquanto ser corporal, significa nãoliberdade. Pois esta se fundamenta na submissão à vontade de outrem como expressão de sua própria vontade. Por outro lado, sendo ou não cristão, estando na condição de autoridade, dispõe da sua autonomia, mesmo como alguém que se dá a conhecer no seu modo de ser corporal. Mas de que modo podemos conceber a autonomia daquele que está somente para servir em sua condição de alguém que dispõe de um corpo para ser submetido às autoridades, começando estas pelas dos pais e indo até às dos mandatários do poder político e religioso?

Isso se faz possível porque a necessária obediência à ordem social previamente estabelecida, seja a partir de uma "dupla moral”, em Lutero, ou da fundamentação moral, em Calvino, nega qualquer possibilidade de revolta por parte do povo, mesmo quando reconhece a necessidade dessa revolta por parte dos magistrados da escala inferior, mas nunca permitida ao povo ou ao seu possível representante. Lutero parte de uma duplicidade moral fundada na liberdade, refletida na relação íntima do homem com Deus, e a não-liberdade, em que se funda a relação do homem com a ordem social estabelecida pelos próprios homens sob o consentimento divino. Esta relação se dá entre a superpessoa e a subpessoa, estando esta submetida àquela. Isto se sustenta pela necessidade da relação hierárquica entre o homem e a autoridade, segundo Calvino, que segue o que tinha sido posto por Lutero, para o qual a autoridade se identifica com as instituições ou ofícios que assumem os homens para a manutenção da ordem que eles próprios criaram. 


\section{OO DEVIR EDUCAÇÃO \\ ISSN: 2526-849X}

Essa relação hierárquica, para Lutero e Calvino, vai se fazendo pela relação da superpessoa com a subpessoa, ao tempo que a superpessoa se põe como autoridade que representa o Estado ou outras instituições em que se estabelecem os poderes de governo e de mando, seja do pai, do chefe ou do patrão, ou seja, daquele que manda para outros obedecerem. E a obediência dos que se subordinam é compreendida como virtude que garante a manutenção da ordem, para a qual são postos os comandos. Estes começam pelos pais, mas sobrepondo-se o pai, sexo masculino, modelo a ser seguido por toda hierarquia sob o comando de um senhor: aquele que manda com vistas à necessária, e indispensável, obediência dos que estão postos como subpessoas a serviço de quem dita as ordens a serem obedecidas.

A necessidade dessa relação se sustenta no conceito burguês de liberdade que fundamenta a autoridade burguesa. Nesta, a liberdade se transfere para a esfera "íntima" da pessoa, consagrando a submissão do "homem externo" ao sistema terreno. Ao ocorrer a transferência da liberdade para a esfera íntima, a não-liberdade, ao tempo que a liberdade, é transferida para a autoridade terrena pela autoridade privada e pela razão com que se separa a pessoa da obra. Dá-se aí a separação da pessoa e seu ofício, firmando-se uma "dupla moral". Portanto, justificam-se, de acordo com Lutero, a não-liberdade e a não-igualdade, tendo como consequência tanto a liberdade quanto a igualdade "íntimas". Ou seja, ao mesmo tempo em que o cristão é senhor livre de todas as coisas, é servidor de todas as coisas e, por isso, sujeito a todas as coisas.

Trata-se aqui da contraposição das determinações próprias da liberdade interna em relação à liberdade externa. Nega-se assim um ser livre e exterior, não sendo possível a alma ser atingida por alguma coisa exterior com vista à sua libertação, pois a liberdade e a prisão do cristão não são corpóreas. Assim sendo, segundo Lutero, na fé se fundamenta a liberdade cristã, não havendo necessidade de obra alguma para que a salvação se justifique. Portanto, mesmo livre, o cristão deve se tornar servo de boa vontade, colocando-se à servidão voluntária do cristão diante da autoridade na vida terrena.

Nisto está a explicação da necessidade da obediência à autoridade, sendo pecado maior a desobediência, ao passo em que a honra, expressa pela submissão ao superior, é bem mais significante que o amor. Calvino diz que é na autoridade do pater famílias que a majestade temível de Deus se manifesta, corroborando com o entendimento de Lutero, para quem vale mais a honra que o amor, pois, na honra, está a docilidade, a timidez e a humildade, que não se limitam ao amor. 


\section{QO DEVIR EDUCAÇÃO \\ ISSN: 2526-849X}

\section{Fundamentos morais a partir da concepção de liberdade}

Reportando-se à perspectiva de uma "dupla moral", Marcuse chama a atenção para a contraposição entre a liberdade exterior e a liberdade interior que é referida por Lutero. Observando a contraposição entre essas liberdades, constata que as determinações que mais se aproximam da liberdade interior se contrapõem à liberdade exterior "como negações de um simples ser livre exterior" (MARCUSE, 1961, p. 61). Assim, de acordo com Lutero, o cristão não pode tornar livre qualquer coisa exterior, porque nada exterior atinge a sua alma. Ou seja, a liberdade do cristão e a sua "prisão" são corpóreas. Portanto, "nenhuma coisa externa "chega até a alma, para libertá-la"” (LUTERO, apud MARCUSE, 1981, p. 61). Marcuse (Ibid., p. 61) observa então que "A alma e sua liberdade não podem ser atingidas por qualquer coisa que exista no mundo ou que dele venha [...]”. Trata-se, para ele, de uma frase terrível que "possibilita a desvalorização da miséria externa sendo acompanhada por uma justificação transcendental”.

Assim, para Lutero, é próprio do homem o sentido positivo e negativo da liberdade, o que corresponde esse duplo sentido da moral. E observa Marcuse que é partindo desse sentido da moral que Lutero diz que o homem, estando encerrado em seu interior, é tão "livre sobre todas as coisas exteriores que ele se torna livre delas, que não mais as 'tem', não mais tem poder sobre elas" (MARCUSE, 1981, p. 61). Ou seja, o homem não precisa mais das coisas nem das obras, não porque as tem ou porque exerce seu poder sobre elas, mas por não haver necessidade delas em sua liberdade interior, autossuficiente. Para Marcuse, essa liberdade interior parece se transformar em liberdade exterior, pois abre-se o terreno da liberdade exterior sob o ponto de vista da salvação da alma. É como se disséssemos da liberdade vista sob o ponto de vista negativo, segundo o qual, ser livre significa ser livre de. A partir do momento que o homem se coloca na condição de ser livre das coisas e das obras, afirma-se a liberdade no modo de ser não-liberdade, que se pode conceber como liberdade exterior próprio do cristão segundo Lutero.

Em meio ao sistema de hierarquização, o homem depara-se com a dignidade do ofício da autoridade não equivalendo à dignidade da pessoa que exerce o ofício. Configurando-se na hierarquização as relações entre superpessoa e "subpessoa", convém a submissão da pessoa à 'superpessoa' como expressão da sua não-liberdade que é a liberdade exterior como não- 


\section{QO DEVIR EDUCAÇÃO \\ ISSN: 2526-849X}

dependência da alma ao que lhe é exterior. Ou seja, "no que diz respeito à dignidade 'interior', ela pode estar muito acima da autoridade. Apesar disso, tem que prestar sua obediência absoluta" (MARCUSE, 1981, p. 65).

A obrigatoriedade dessa obediência explica a oposição de Lutero em relação aos camponeses, quando estes se revoltaram contra a "liberdade cristã": esta liberdade não os tornava livres, mantendo-se a sua escravidão. Isto significa, como diz Marcuse, que "O reconhecimento da não-liberdade real (especialmente da não-liberdade criada pelas relações de propriedade) faz parte do sentido desse conceito de liberdade” (1981, p. 67). Portanto, segundo ele, "se a não-liberdade 'exterior' pode atingir o verdadeiro ser do homem, então isso quer dizer que se decide sobre a liberdade e a não-liberdade do homem na própria terra, na prática social, que o homem pode tornar-se livre de Deus e livre para si mesmo, no mais perigoso dos sentidos da palavra livre" (1981, p. 67).

Considere-se, então, a advertência feita pelo próprio Lutero ao se referir à “independentização e coisificação da autoridade terrena": "a violação da autoridade, a sublevação e a desobediência se tornam pecado social em geral, 'pecados maiores que o assassinato, a incastidade, o roubo, o engodo e tudo mais que possa ser concebido neste sentido"” (LUTERO, apud MARCUSE, 1981, p. 69). Calvino abandona o duplo sentido da moral, mas mantém firme esse entendimento. Pois, para ele toda liberdade humana se firma como não-liberdade. Assim sendo, Lutero e Calvino compartilham o entendimento sobre a doutrina do servum arbitrium. Para Marcuse, isso "abriga uma nova contradição", levando-o a perguntar: "Como é possível conceber uma auto-responsabilidade do homem diante da determinação completa da vontade humana? (MARCUSE, 1981, p. 77). Para os dois reformadores, a responsabilidade do homem deve ser salva para que seja atendida a exigência da doutrina cristã do pecado e da culpa, bem como a exigência do castigo e da salvação. E, para Calvino, trata-se de uma "necessidade espontânea". Isto significa, segundo Marcuse (1981, p. 78), que a “A vontade humana está necessariamente condenada e escolhe necessariamente o mal. Isso, porém, não quer dizer que ele escolhe o mal coagido, 'contra a vontade'; sua sujeição ao pecado é uma 'servidão voluntária"”.

O exercício da autoridade que faz da pessoa supepessoa no seu ofício faz também de outras pessoas subpessoas no seu vínculo com as instituições. Estando a família como primeira referência, considera-se as relações entre pais e filhos (e entre os cônjuges) estando estes e a esposa (subpessoas) em relação ao pai e marido (superpessoa). Nessa relação surge a necessidade de "servidão voluntária", que nos remete à servidão à escola e ao Estado e 


\section{QO DEVIR EDUCAÇÃO \\ ISSN: 2526-849X}

também à Igreja. Chegamos assim à "necessidade" de uma "Escola Sem Partido" contrapondo-se à dialogicidade na educação que passa a se confundir com adestramento. Surge então o Movimento "Escola Sem Partido" para alertar os professores em relação ao que eles devem ensinar nas escolas. Assim se faz necessária a submissão de professores e estudantes às deliberações da autoridade sobre o que é ou não permitido em sala de aula, desaparecendo a autonomia do professor e o espaço para o diálogo.

\section{A concepção de educação e de escola desse Movimento Escola Sem Partido}

Com vista no exposto acima, cabe então perguntar o que é e como surgiu essa "Escola Sem Partido"? Trata-se do modelo de Escola proposto pelo Movimento Escola sem Partido, que surgiu em 2004, idealizado por Miguel Nagib, Procurador do Estado de São Paulo. Segundo Lucila Conceição Pereira, ele propôs este Movimento considerando que "muitos professores sob o pretexto de despertar a consciência crítica dos estudantes acabam deixando o processo educativo de lado em prol da disseminação de propaganda partidária e de ideais de esquerda". 2

Em 2014, Nagib foi convidado por Flávio Bolsonaro, Deputado Estadual do Rio de Janeiro, para escrever o PL 2974/2014 a ser apresentado à Assembleia Legislativa, enquanto o seu irmão, Carlos Bolsonaro, vereador do Rio de Janeiro, fez o mesmo, encaminhando à Câmara Municipal o PL 864/2014. De lá para cá, observa Cleomar Manhas (2016, p. 20), a "tal proposta já se espalhou por diversas câmaras municipais e assembleias legislativas. Em âmbito nacional, o deputado Izalci (PSDB/DF) apresentou o PL 867/2015 à Câmara Federal, que altera a Lei de Diretrizes e Bases da Educação". Considere-se ainda o Projeto de Lei no. 7180/2014 que está com a Comissão Especial da Câmara Federal para analisá-lo e que cancelou a reunião em 08 de agosto de 2018, na qual estaria em discussão o Relatório que fora publicado em 08 de maio de 2018. Diz Ingrid Matuoka (2018) ${ }^{3}$ que, "Além deste projeto de lei que tramita na Câmara dos Deputados, há outros projetos de lei em andamento: 25 estaduais, 110 municipais, e 13 no Congresso".

Em relação ao que significa essa Escola, diz Cleomar Manhas (Ibidem): "Basicamente, trata-se de uma falsa premissa, pois não diz respeito a não partidarização, mas sim à retirada

\footnotetext{
${ }^{2}$ Disponível em: https://www.infoescola.com/educacao/escola-sem-partido/. Acesso em 24 de setembro de 2018.

${ }^{3}$ Disponível em: http://educacaointegral.org.br/reportagens/por-que-o-escola-sem-partido-vai-contra-o-papel-daescola/. Acesso em: 23 de setembro de 2018.
} 


\section{QO DEVIR EDUCAÇÃO \\ ISSN: 2526-849X}

do pensamento crítico, da problematização e da possibilidade de se democratizara escola, esse espaço de partilhas e aprendizados ainda tão fechado, que precisa de abertura e diálogo" (MANHAS, 2016, p. 16).

O Movimento "Escola Sem Partido" afirma que a escola atual, no Brasil, tem se pautado pela doutrinação. Daniel Cara vê nisto "uma escola sem educação": "Os projetos de lei do Escola Sem Partido se baseiam na acusação de que há uma doutrinação moral e ideológica de esquerda nas escolas brasileiras" (2016, p. 44). Daí propõem a vigilância aos professores, como ele observa: "Diante disso, os professores devem ser vigiados e controlados no exercício de sua profisssão, por meio da imposição de limites à liberdade de cátedra - um dos pilares fundamentais do magistério" (2016, p. 44). Ou seja, como diz Frei Beto, "a proposta do Escola Sem Partido é impedir que os professores eduquem seus alunos com consciência crítica" (2016, p. 66).

Como diz Rodrigo Ratier (2016, p. 30), a doutrinação é uma "palavra que remete à pregação", o que é, segundo ele, "algo inadequado em qualquer aula”. E ele acrescenta: “A pluralidade de visões e o questionamento de cada uma delas é o caminho mais fértil para levar os alunos a pensar por conta própria [...]”. Mas o que justificaria a proposta de uma Escola Sem Partido, quando, ao contrário do que dizem, abre-se espaço cada vez maior para essa "pluralidade de visões" acompanhada do indispensável questionamento para que os alunos aprendam a pensar por si mesmos? É o próprio Ratier que nos chama a atenção para o contraditório: "Embora o Escola Sem Partido diga receber numerosas denúncias, o site do movimento registra somente 33. O Brasil possui mais de 45 milhões de estudantes e daí conclui: "É preciso ter dados mais sólidos para separar casos isolados de tendências e, também, para ter uma visão mais clara sobre se, onde e em quais situações o problema acontece" (RATIER, 2016, p. 31).

Quanto à alegação de doutrinação esquerdista, Ratier diz que não há nenhuma comprovação em relação a isso. Ao contrário disso, observa: "uma pesquisa do Instituto Datafolha, realizada em 2014, mostra que há mais brasileiros afinados com ideias defendidas pela direita $(45 \%)$ do que à esquerda (35\%) em temas relativos a comportamento, valores e economia". Comparando com pesquisas anteriores, conclui: "Em relação a anos anteriores, há um avanço da direita e um recuo da esquerda” (Ibid., p. 32). Ou seja, não há vestígios de uma doutrina à esquerda, quando parecem que a maioria tem aderido à direita, como observa Leonardo Sakamoto (2016, p. 13): "se existe doutrinação esquerdista, ela está dando muito, 


\title{
QO DEVIR EDUCAÇÃO \\ ISSN: 2526-849X
}

mas muito errado - uma pesquisa Datafolha, de dois anos atrás, e o próprio mapa eleitoral das últimas eleições registram um avanço da direita e um recuo da esquerda".

Portanto, considerando o proposto pelo Escola Sem Partido, Fernando Abrucio diz que essa escola deveria se chamar Escola Sem Sentido, e acrescenta: "Ressalto que nenhum país com destaque em avaliações internacionais no plano da educação se orienta por propostas nos termos do Escola Sem Partido" (2016, p. 60) . Pois, segundo ele, “A liberdade e a criatividade do professor, aliadas a um controle de seus resultados pedagógicos (o quanto conseguem melhorar o aprendizado dos alunos), aparecem como elementos importantes em casos de sucesso" (2016, p. 60). Daí a conclusão dele: “Docentes que estimulem alunos curiosos e com consciência crítica, produzindo pessoas que saibam lidar com a diversidade de opiniões, são o protótipo esperado por governos bem sucedidos em políticas educacionais” (Ibid., p. 60-61).

Mas o Escola Sem Partido é contra o abuso da liberdade de ensinar, que se configura como doutrinação por parte dos professores, o que leva à seguinte afirmação:

\begin{abstract}
A doutrinação política e ideológica em sala de aula ofende a liberdade de consciência do estudante; afronta o princípio da neutralidade política e ideológica do Estado; e ameaça o próprio regime democrático, na medida em que instrumentaliza o sistema de ensino com o objetivo de desequilibrar o jogo político em favor de um dos competidores". (ESCOLA SEM PARTIDO $)^{4}$
\end{abstract}

Como dizem os próprios propositores dessa "Escola", isso já está previsto nos dispositivos constitucionais. Por outro lado, diferentes pesquisas dizem não haver essa doutrinação referida nas escolas brasileiras. Todavia, adentrando mais na questão, fica claro quais são os verdadeiros propósitos: repassar, nas aulas, apenas o que seja compatível com a ideologia da escola, pois os conteúdos das disciplinas obrigatórias não podem contrariar "as convicções morais dos estudantes ou de seus pais”. Valem-se do Art. 12 da Convenção Americana sobre Direitos Humanos que diz que "os pais têm direito a que seus filhos recebam a educação religiosa e moral que esteja de acordo com suas próprias convicções". Confundem aqui o direito dos pais educarem os seus filhos com o despertar da consciência crítica para a diversidade de entendimento sobre a moral, a religião, a economia, a política etc. Consideram esse despertar do senso crítico "abuso da liberdade de ensinar".

\footnotetext{
${ }^{4}$ Disponível em: https://www.programaescolasempartido.org/. Acesso em 17 de setembro de 2018.
} 


\section{OO DEVIR EDUCAÇÃO \\ ISSN: 2526-849X}

Ao trazer para a discussão o Relatório referente ao Projeto de Lei $n^{\circ}$. 7180/2014, conhecido como Escola Sem Partido, publicado no dia 8 de maio de 2018, Ingrid Matuoka (2018) considerou o que disse a mestranda em Ensino de História pela Universidade do Estado do Rio de Janeiro (UERJ) e integrante do "Professores contra o Escola sem Partido e do Movimento Educação Democrática", Renata Aquino ${ }^{5}$

Os professores não se oporiam a discutir a ética da profissão, como ensinar, equilibrar a construção de conhecimentos com a função social da escola, debates desejáveis e naturais. Mas esse texto toma outro caminho, que é violento: o de proibir que se fale em determinados assuntos. (AQUINO, apud MATUOKA, 2018, p. 18).

E ela continua dizendo ser difícil dar sentido para a aprendizagem sem falar de temas atuais, do contexto, como quer o movimento "O Escola Sem Partido", que insiste em afirmar que o professor só deve falar dos conteúdos curriculares. E acrescenta: "Ter a liberdade para discutir questões variadas em sala de aula não é o mesmo que obrigar o aluno a pensar de determinada maneira". Daí, conclui: "Nós mal conseguimos obrigá-los a fazer a tarefa de casa, quem dirá a pensar de um jeito ou de outro" (Ibidem).

Daniel Cara, defendendo a educação escolar como representante do conjunto da sociedade, lembra que, segundo a Constituição brasileira, "o Brasil precisa ser um país pautado pela justiça social”, conforme as palavras de Ingrid Matuoka (Ibidem). Portanto ele afirma não ser "justo nem adequado" uma família não aceitar a justiça social, ou ter "uma postura discriminatória". Nesses casos, segundo ele, "a moral familiar deve ser enfrentada e não pode se sobrepor à educação escolar. A família precisa ser considerada como parte da sociedade. Mas não pode ser maior do que o todo" (apud Matuoka, Ibidem). Todavia, isto é inadmissível para o "Escola Sem Partido".

Gaudêncio Frigotto, referindo-se à Escola "sem" Partido, a contextualizou no que temos hoje de imposição do sistema capitalista em uma de suas crises históricas, "não mais cíclica", como as anteriores, mas uma crise "contínua, universal e global cada vez mais profunda". Daí ser necessário aos capitalistas "aumentar a desigualdade e as mais diferentes formas de violência, no limite pela eliminação de quem se opõe", para que haja aumento dos seus

\footnotetext{
${ }^{5}$ Disponível em: http://educacaointegral.org.br/reportagens/por-que-o-escola-sem-partido-vai-contra-o-papel-daescola/. Publicado em 24/05/2018. Acesso em: 23 de setembro de 2018.
}

Revista Devir Educação, Lavras, vol.3, n.1, p.140-154 jan./jun., 2019. 


\section{Q DEVIR EDUCAÇÃO \\ ISSN: 2526-849X}

lucros: "Disto decorre a mudança de estratégias para legitimar a violência do Estado" (FRIGOTTO, 2017, p. 30).

Segundo ele, "As teses do Escola sem Partido não podem ser entendidas nelas mesmas e nem como algo que afeta apenas a escola e os educadores". Ao contrário disto, "um olhar na perspectiva da historicidade dos fatos e fenômenos, vale dizer, das determinações mais profundas e menos visíveis que os constituem, indica-nos que se trata de algo já sedimentado nas relações sociais" (FRIGOTTO, 2017, p. 18). Assim, expressando a anulação da política, faz-se a afirmação de um Estado policial. E isto é necessário para o sistema capitalista. Por isso, em meio às desigualdades, tanto em termos econômicos e sociais, como também em relação à educação e à cultura, isto se firma em pleno século XXI como resultado "de um processo de ditaduras e golpes da classe dominante com objetivo de manter seus privilégios" (Id., ibidem, p. 20).

Frigotto nos diz ainda que é preciso considerar os golpes de Estado e as ditaduras como diferentes mecanismos utilizados no Século XX para "impedir avanços das lutas populares e da classe trabalhadora na busca dos direitos elementares do acesso à terra, comida, habitação, saúde, educação e cultura (Id., ibidem, p. 20). Neste sentido, é possível compreender o Movimento da "Escola Sem Partido" como mais um desses mecanismos em pleno Século XXI, juntamente com o movimento do "Todos pela Educação" que, na verdade, deve ser entendido como "todos pela educação que convém ao mercado" (Ibid., p. 29). Assim, afirma Frigotto "O Escola sem Partido expressa o epílogo de um processo que quer estatuir uma lei que define o que é ciência e conhecimentos válidos, e que os professores só podem seguir a cartilha das conclusões e interpretações da ciência oficial, uma ciência supostamente não neutra" (Ibid., p. 29). A isto acrescenta: "Para isso, manipula até mesmo o sentido liberal de política, induzindo a ideia de que a escola no Brasil estaria comandada por um partido político e seus profissionais e os alunos seres idiotas manipulados" (Ibid., 29).

Frigotto diz ainda que usa aspas no termo "sem" para a denominação Escola sem partido para "sublinhar" o que parece ser, mas não é:

[...] trata-se da defesa, por seus arautos, da escola do partido absoluto e único: partido da intolerância com as diferentes ou antagônicas visões de mundo, de conhecimento, de educação, de justiça, de liberdade; partido, portanto, da xenofobia nas suas diferentes facetas: de gênero, de etnia, da pobreza e dos pobres etc. Um partido que ameaça os fundamentos da liberdade e da democracia. (FRIGOTO, 2017, p. 31). 


\section{QO DEVIR EDUCAÇÃO \\ ISSN: 2526-849X}

\section{Conclusão}

Assim, assentando-se no discurso da neutralidade da escola e do respeito à pluralidade de pensamento em termos de religião, política e moral, etc., recorrem ao conceito de educação e de ensino que, há muito, deveria ter sido superado. A concepção de educação subentendida nesse discurso nada mais é do que adestramento, sendo o ensino uma mera transmissão de conhecimento. Com base nisto, falam de doutrinação por parte dos professores que deve ser evitada, ou que deva ser motivo para a punição de professores que violarem o princípio, tratando de assunto que não seja aquele estabelecido pela escola como conteúdo pedagógico. Por isso o alerta deve estar posto em toda escola, não somente em sala de aula, para que os alunos denunciem quando o professor não estiver fazendo aquilo que lhe fora dito para fazer. Enquanto isto, compete aos professores obedecer às determinações da instituição, não passando isto de garantia de que os alunos não serão despertados para as razões das desigualdades e discriminações sociais em suas diferentes possibilidades de ser, nem contestem os privilégios de uma maioria.

Concebendo-se a liberdade como não-liberdade, aquela compreendida pelos reformadores Lutero e Calvino como liberdade exterior, continuará servindo de instrumento para a garantia de interesses da burguesia detentora do poder econômico, político e cultural, incluso neste último o que é próprio da religião. Tomando-se a ética como prescrição daquilo que tem que ser feito pelo cristão e que deve ser estendido a todos os seres humanos, cabe aos professores, na hierarquia em que se encontram, obedecer, limitando-se suas aulas aos conteúdos previamente estabelecido pela instituição, evitando qualquer possibilidade de questionamento. Afasta-se, pois, toda dialogicidade proposta por Paulo Freire para uma educação libertadora, para dar lugar justamente à educação contestada por Freire como educação bancária. Nesta, segundo Paulo Freire garante-se o lugar da narrativa e da dissertação, ao invés do diálogo, ficando, de um lado, o professor, na sua condição de sujeito, e, do outro, o aluno, na condição de objeto: “A narração, de que o educador é o sujeito, conduz os educandos à memorização mecânica do conteúdo narrado". Continuando com a sua reflexão, ele diz que “a narração os transforma em 'vasilhas', em recipientes a serem ‘enchidos' pelo educador”' (FREIRE, 1991, p. 66). 


\section{QO DEVIR EDUCAÇÃO \\ ISSN: 2526-849X}

Assim, no sistema de hierarquia dos reformadores, como fora observado por Marcuse, os alunos são submetidos à autoridade do professor, assim como este obedece à instituição, o que significa dizer obediência ao Estado ao se colocar a serviço do ofício de autoridade daqueles que governam. E estando a burguesia na condição de governante, compreendemos o que diz Frei Beto "Uma das falácias da direita é professar a ideologia de que ela não tem ideologia. E a de seus opositores deve ser rechaçada" (2016, p. 66). Assim sendo, "é uma velha artimanha da direita" (2016, p. 66) acobertar com palavras a realidade que não lhe convém mudar, de modo "que não se saiba que desigualdade social decorre da opressão sistêmica; a riqueza, do empobrecimento alheio; a homofobia, do machismo exacerbado; a leitura fundamentalista da Bíblia da miopia que lê o texto fora do contexto" (2016, p. 66).

Daí a necessidade de obediência à hierarquia escolar requerida pelo Movimento "Escola Sem Partido". Nela se afirma a liberdade como negação da libertação para qualquer coisa que possa implicar envolvimento com o que seja do interesse dos explorados, descriminados e oprimidos. Ser livre, neste sentido, é optar por não-ser livre. A obediência à hierarquia se configura com liberdade de não-liberdade. Isto significa que está, nessa obrigação de obediência à autoridade posta por Lutero e Calvino, a justificativa para a neutralidade da ideologia do "Escola Sem Partido". A obediência a quem se coloca como superpessoa numa relação de súdito para senhor que se manifesta no modo de ser silencioso, aceitando a ordem imposta sem nenhum questionamento e, portanto, sem nenhuma contestação. Numa "escola sem partido", cumpre-se apenas obedecer aos professores, se alunos, ou obedecer aos gestores, se alunos e professores. Nada há que se possa considerar motivo para a desobediência, pecado maior segundo os reformadores. Nisto vai se fazendo uma fundamentação dos costumes que tem por fim a garantia de uma servidão voluntária, requerida pela lógica da ideologia do "Escola Sem Partido", que prega a neutralidade políticoideológica, como se, nela mesma, não se firmasse o ideológico. Porém, observando-se o proposto pelo pensamento de Lutero, e seguido por Calvino, isto se faz necessário no portarse do cristão que só deve reconhecer em si a sua liberdade interior face à não-liberdade do mundo humano, que expressa toda exterioridade do cristão.

\section{Referências}

Revista Devir Educação, Lavras, vol.3, n.1, p.140-154 jan./jun., 2019. 


\section{QO DEVIR EDUCAÇÃO \\ ISSN: 2526-849X}

ABRUCIO, Fernando. Contra escola sem sentido. In: A ideologia do movimento Escola Sem Partido: 20 autores desmontam o discurso. AÇÃO EDUCATIVA ACESSORIA PESQUISA E INFORMAÇÃO (Org.). São Paulo: Ação Educativa, 2016, p.168.

BETTO, Frei. "Escola Sem Partido"? In: A ideologia do movimento Escola Sem Partido: 20 autores desmontam o discurso. AÇÃO EDUCATIVA ACESSORIA PESQUISA E INFORMAÇÃO (Org.) São Paulo: Ação Educativa, 2016, p.168.

CARA, Daniel. O Programa "Escola Sem Partido" quer uma escola sem educação. In: A ideologia do movimento Escola Sem Partido: 20 autores desmontam o discurso. In: AÇÃO EDUCATIVA ACESSORIA PESQUISA E INFORMAÇÃO (Org.). São Paulo: Ação Educativa, 2016, p.168.

FREIRE, Paulo. Pedagogia do oprimido. 10 ed. Rio de Janeiro: Paz e Terra, 1981.

FRIGOTTO, Gaudêncio A gênese das teses do Escola sem Partido: esfinge e ovo da serpente que ameaçam a sociedade e a educação. In: FRIGOTTO, Gaudêncio (Org.). Escola "sem" partido: esfinge que ameaça a educação e a sociedade brasileira. Rio de Janeiro: UERJ, LPP, 2017. $144 \mathrm{p}$

LUTERO, Martin. Da liberdade cristã. Trad. Leônidas Boutin, Pastor Heinz Soboll. 3 ed. São Leopoldo, RS: Sinodal, 1979.

MANHAS, Cleomar. Nada mais ideológico que "Escola Sem Partido". In: A ideologia do movimento Escola Sem Partido: 20 autores desmontam o discurso. AÇÃO EDUCATIVA ACESSORIA PESQUISA E INFORMAÇÃO (Org.). São Paulo: Ação Educativa, 2016, p. 168.

MARCUSE, Herbert. Ideias sobre uma teoria crítica da sociedade. Trad. Fausto Guimarães. 2 ed. Rio de Janeiro: Zahar, 1981, p. 168.

RATIER, Rodrigo. 14 perguntas e respostas sobre o "Escola Sem Partido". In: A ideologia do movimento Escola Sem Partido: 20 autores desmontam o discurso. AÇÃO EDUCATIVA ACESSORIA PESQUISA E INFORMAÇÃO (Org.). São Paulo: Ação Educativa, 2016, p. 168.

SAKAMOTO, Leonardo. "Escola Sem Partido": doutrinação comunista, coelho da páscoa e Papai Noel. In: A ideologia do movimento Escola Sem Partido: 20 autores desmontam o discurso. AÇÃO EDUCATIVA ACESSORIA PESQUISA E INFORMAÇÃO (Org.). São Paulo: Ação Educativa, 2016, p. 168.

ESCOLA SEM PARTIDO. Por uma lei contra o abuso da liberdade de ensinar.

Disponível em: <https://www.programaescolasempartido.org/>. Acesso em: 17 Set. 2018.

INFOESCOLA. Movimento Escola sem Partido. Disponível em:

<https://www.infoescola.com/educacao/escola-sem-partido/>. Acesso em: 24 Set. 2018.

Revista Devir Educação, Lavras, vol.3, n.1, p.140-154 jan./jun., 2019. 


\section{OO DEVIR EDUCAÇÃO}

ISSN: 2526-849X

BRASIL. Comissão especial destinada a proferir parecer ao Projeto de Lei $\mathbf{n}^{\mathbf{0}} \mathbf{7 1 8 0 .}$

Disponível em: <http://www.camara.leg.br/internet/comissoes/comissoes-

especiais/historico/55/p1718014.pdf>. Acesso em: 24 Set. 2018.

MATUOKA, Ingrid. Por que o Escola Sem Partido vai contra o papel da escola.

Disponível em: <http://educacaointegral.org.br/reportagens/por-que-o-escola-sem-partido-vaicontra-o-papel-da-escola/>. Acesso em: 23 Set. 2018. 